\title{
HUBUNGAN ANTARA PERSEPSI SISWA TERHADAP BIMBINGAN KONSELING DENGAN INTENSITAS PEMANFATAN LAYANAN KONSELING INDIVIDUAL DI KELAS VIII SMPN 9 PALANGKA RAYA
}

\author{
M. Hariadi Akbar', Merson U. Sangalang², Esty Pan Pangestie 3 \\ 'Universitas Palangkaraya, FKIP, Prodi BK \\ 'Universitas Palangkaraya, FKIP, Prodi BK \\ 'Universitas Palangkaraya, FKIP, Prodi BK \\ E-mail:aridhonky@gmail.com
}

\begin{abstract}
ABSTRAK
Persepsi merupakan proses subjektif pengolahan bagaimana manusia dapat menilai suatu objek. Banyak hal yang mempengaruhi persepsi, antara lain stimulus yang ada, faktor lingkungan, pengamatan serta pengalaman. Perilaku muncul berdasarkan persepsi yang dimiliki oleh masing-masing individu. Fenomena yang terjadi di SMPN 9 Palangka Raya yaitu siswa enggan berkonsultasi secara suka rela dengan guru BK yang artinya siswa hanya datang ke guru BK jika dipanggil karena telah melakukan pelanggaran.Penelitian ini bertujuan untuk memperoleh gambaran hubungan antara persepsi siswa dengan layanan bimbingan konseling di Kelas VIII SMPN 9 Palangka Raya.Populasi penelitian ini adalah siswa SMPN 9 Palangka Raya yang terdiri dari 3 (tiga) kelas VIII-A VIII-B VIII-C yang berjumlah 72 siswa. Sedangkan sampel penelitian dengan menggunakan total sampling yaitu menarik semua populasi sebagai sampel.Teknik Pengumpulan data pada penelitian menggunakanangket dan wawancara. Selanjutnya hasil dari data angket dianalisis dengan teknik perhitunganproduk moment diperoleh nilai $r$ hitung yaitu sebesar $0,84 \mathrm{I}$. Selanjutnya nilai $r$ hitung tersebut dikonsultasikan dengan $r$ tabel produk moment dengan $\mathrm{N}$ = 72 dan taraf kebenaran I \%, yaitu, 0,368. Didapat hasil yaitu, 4,84I >0,368. Kesimpulan dari analisis di atas, yaitu ada hubungan yang siginifikan antara persepsi siswa terhadap layanan BK yang ada di SMPN 9 Palangka Raya.
\end{abstract}

Kata Kunci: Persepsi Siswa terhadap bimbingan Konseling; konseling individu

\section{THE RELATIONSHIP BETWEEN STUDENTS PERCEPTION TOWARDS COUNSELING WITH THE INTENSITY OF THE INDIVIDUAL COUNSELLING SERVICES IN CLASS VIII SMPN PALANGKA RAYA}

\begin{abstract}
Perception is a subjective process of processing how humans can judge an object. Many things affect perception, including existing stimuli, environmental factors, observations and experiences. Behavior appears based on the perceptions of each individual. The phenomenon that occurs at SMPN 9 Palangka Raya is that students are reluctant to consult voluntarily with counseling teachers, which means that students only come to the counseling teacher when called because they have committed a violation. This study aims to obtain an overview of the relationship between student perceptions and counseling guidance services in Class VIII. SMPN 9 Palangka Raya. The population of this study were students of SMPN 9 Palangka Raya which consisted of 3 (three) classes VIII-A VIII-B VIII-C, totaling 72 students. While the research sample using total sampling, which is to draw all the population as a sample. Data collection techniques in research using a draw and interviews. Furthermore, the results of the questionnaire data were analyzed using the product moment calculation technique, the $r$ value was obtained, namely $0.84 I$. Furthermore, the calculated $r$ value is consulted with the product moment table $r$ with $N=72$ and the level of truth is $1 \%$, namely, 0.368 . The results obtained were, $4,84 I>0.368$. The conclusion from the above analysis is that there is a significant relationship between students' perceptions of BK services at SMPN 9 Palangka Raya.
\end{abstract}

Keywords: Student Perceptions of Counseling guidance; individual counseling 
M. Hariadi Akbar, Merson U. Sangalang \& Esty Pan Pangestie Jurnal Pandohop

Vol. I, No. I, Tahun 202 I

\section{PENDAHULUAN}

Dalam setting pendidikan di sekolah para siswa sering menghadapi masalah-masalah yang kompleks sebagai akibat dari perubahan sosial yang penuh tantangan, tuntutan dan pilihan. Kesemuanya itu terkadang menimbulkan keraguan terhadap masa depannya, bahkan menimbulkan krisis jati diri. Salah satu bantuan yang perlu diberikan untuk membantu siswa mengatasi semua itu adalah bimbingan konseling. Bimbingan konseling dirasakan sangat perlu di lembaga-lembaga pendidikan, karena bimbingan merupakan kegiatan bantuan yang diberikan kepada individu secara terus menerus dalam menghadapi persoalan-persoalan yang timbul dalam hidupnya.

Sekolah merupakan tempat berkumpulnya siswa yang berlatar belakang berbeda-beda antara satu dengan yang lainnya, baik dari segi keadaan keluarga, ekonomi, adat istiadat, agama maupun dari segi psikologis seperti persepsi, bakat dan minatnya. Adanya perbedaan tersebut, maka tidak mustahil pula akan timbul berbagai macam problema dalam hidupnya. Namun adakalanya mereka dapat mengatasi dan ada pula yang tidak dapatmengatasinya sehingga mereka memerlukan bantuan orang lain yang mampu memberikan alernatif, serta solusi pemecahannya melalui bimbingan arahan-arahan, nasehat dan penyuluhan.

Salah satu bentuk layanan yang perlu diterapkan adalah pelayanan bimbingan belajar. Agar layanan tersebut dapat mencapai hasil yang bail maka perlu integrasi antara guru bidang studi dan konselor dalam pelaksanaannya. Bimbingan merupakan suatu proses membantu individu melalui usahanya sendiri untuk menemukan dan mengembangkan kemampuannya agar memperoleh kebahagiaan pribadi dan kemanfaatan sosial (Hallen dalam Retnanto, 20I5). Bimbingan merupakan suatu proses membantu individu melalui usahanya sendiri untuk menemukan dan mengembangkan kemampuannya agar memperoleh kebahagian pribadi dan kemanfaatan sosial. Dengan membantu siswa mengenal bakat, minat dan kemampuannya, serta memilihdan menyesuaikan diri dengan kesempatan pendidikan untuk tuntutan dunia kerja mendatang maka pada dasarnya pelaksanaan bimbingan merupakan program bantuan bagi siswa yang penting dan bermanfaat. Namun fenomena yang tampak sehubungan dengan adanya Bimbingan dan Konseling (BK) ini adalah kurangnya minat dan perhatian para remaja pada program ini.

Berdasarkan kurikulum SMU mengenai petunjuk pelaksanaan bimbingan konseling tahun 1994, dinyatakanbahwa program bimbingan dan konseling ini pada dasarnya merupakan bimbingan belajar- dan bimbingan karir, yang berupaya membentuk perkembangan siswa secara optimal. Dengan membantu siswa mengenal bakat, minat dan kemampuannya, serta memilih dan menyesuaikan diri dengan kesempatan pendidikan untuk tuntutan dunia kerja mendatang maka pada dasarnya pelaksanaan bimbingan merupakan program bantuan bagisiswa yang penting dan bermanfaat. Namun fenomena yang tampak sehubungan dengan adanya Bimbingan dan Konseling (BK) ini adalah kurangnya minat dan perhatian para remaja pada program ini. Persepsi merupakan awal dari proses interaksi manusia dengan lingkungannya. Persepsi merupakan proses subjektif pengolahan bagaimana manusia dapat menilai suatu objek. Banyak hal yang mempengaruhi persepsi, stimulus yang ada, faktor lingkungan, pengamatan serta pengalaman.Pengertian bimbingan dalam arti bahasa Nampak menunjukkan guru BK posisinya aktif, seperti menunjukan jalan keluar penyelesaian masalah, menentukan keputusan akhir yang harus dibuat konseli, mengatur cara konseli menyesaikan masalah, memberikan komando, mengatur dan memberikan 
M. Hariadi Akbar, Merson U. Sangalang \& Esty Pan Pangestie Jurnal Pandohop

Vol. I, No. I, Tahun 202 I e-ISSN .xxxxxxxxx

nasehat. Sedangkan secara istilah, 'bimbingan' diartikan dengan pengertian yang beragam oleh para ahli namun dengan satu kata kunci yang sama yaitu “membantu'.

Sejalan dengan pemaknaan tersebut Prayitno dan Erman Amti (dalam Pratama et al., 2016) mengartikan bimbingan sebagai proses pemberian bantuan yang dilakukan oleh orang yang ahli kepada seorang atau beberapa orang individu, baikanak-anak, remaja, maupun dirinya sendiri dan mandiri dengan memanfaatkan kekuatan individu dan sarana yang ada dan dapat dikembangkan berdasarkan norma-norma yang berlaku.

Bimbingan dikatakan sebagai suatu "proses" pada pendapat diatas, hal tersebut memberikan gambaran bahwaaktivitas bimbingan sebagai serangkaian tindakan yang dilakukan untuk mencapai suatu hasil tertentu. Penjelasan ini menegaskan bahwa aktivitas bimbingan bukan pekerjaan instan, bukan selesai dengan sekali pertemuan, bukan pekerjaan yang berakhir setelah konseli mengemukakan masalah dan konselor memberikan nasehat. Tetapi lebih dari itu bimbingan merupakan tindakan yang berkelanjutan/beseri yang dimulai dari upaya pengenalan masalah sampai dengan memilih dan menentukan alternative tindakan yang di rasa tepat dan dapat dipakai untuk menyelesaikan masalah.

Persepsi merupakan proses subjektif pengolahan bagaimana manusia dapat menilai suatu objek. Banyak hal yang mempengaruhi persepsi, stimulus yang ada, faktor lingkungan, pengamatan serta pengalaman. seseorang berprilaku berdasarkan persepsi masing-masing (Robbin dalam Ardi, 20II). Persepsi siswa terhadap BK ini perlu diketahui dengan pertimbangan bahwa siswa adalah sasaran utama dari program Bimbingan dan Konseling (BK) yang diberikan oleh pihak sekolah, sehingga dengan demikian dapat dilakukan beberapa penyesuaian yang tepat agar BK ini mendapatkan apresiasi yang menarik oleh siswa.

Fenomena yang ada di SMPN 9 Palangka Raya juga dihadapi dengan kurangnya kesadaran siswa tentang pentingnya layanan konseling individual, yang mana siswa enggan berkonsultasi dengan guru BK, sekalipun siswa ada berkonsultasi dengan guru BK Cuma apabila sudah dipanggil atau ketahuan melakukan pelanggaran sekolah sehingga dengan cara yang demikian siswa akan kurang maksimal dalam melakukan hubungan layanan dengan guru. Karena bukan tanpa kesadarannya sendiri. Jadi dengan demikian intesitas pemanfaatan layanan konseling individualnya kurang. Dari ketiga kelas yaitu kelas VIIIA, VIII-B, VIII-C, siswa yang terbilang sering atau memanfaatkan layanan bimbingan konseling disekolah Cuma sebagian kecil saja, sisanya siswa akan memanfaatkan layanan bimbingan konseling Cuma apabila sudah ada masalah atau dipanggil gurunya. Dari total 72 siswa Cuma 10 sampai 15 siswa saja yang memanfaatkan layanan bimbingan konselingnya dengan baik atau dengan kemauannya sendiri.

Persepsi yang berkembang dikalangan siswa tentang bimbingan konseling disekolah tergolong kurang baik, yang mana siswa beranggapan bahwa siswa yang berurusan dengan guru BK atau yang mengikuti layanan-layanan BK adalah siswa yang bermasalah, sehingga susah bagi guru untuk memberikan layanan secara maksimal, karena siswa sudah bernggapan dirinya adalah siswa yang bermasalah, tidak jarang siswa juga berasumsi bahwa guru BK adalah polisi sekolah, dengan demikian kebanyakan siswa akan menghindari gurunya. Sedangkan apabila siswa dengan kesadarannya sendiri mau dan bisa berkonsultasi dengan guru BK apabila merasa ada sesuatu yang kurang terhadap dirinya baik itu dalam masalah Akademiknya atau masalah-masalah 
M. Hariadi Akbar, Merson U. Sangalang \& Esty Pan Pangestie Jurnal Pandohop

Vol. I, No. I, Tahun 202 I e-ISSN .xxxxxxxxx

yang lain maka suatu Intensitas pemanfaatan proses layanan akan berjalan dengan baik.

\section{METODOLOGI}

Metode penelitian yang digunakan adalah metode penelitian deskriptif dengan pendekatan kualitatif. Dalam (Sugiyono, 2018) bahwa kedudukan subjek penelitian pada penelitian sangat penting karena data tentang variable yang diteliti berada dan diamati oleh peneliti, sampel dalam penelitian kualitatif bukan responden, tetapi sebagai narasumber atau partisipan, informan, teman dan guru dalam penelitian. Subjek penelitian ini adalah berjumlah 72 siswa kelas VIII SMPN 9 Palangka Raya Tahun Ajaran 2018/2019.

Teknik pengumpulan data merupakan cara Alat yang digunakan untuk mengumpulkan data di dalam penelitian ini yaitu menggunakan angket. Angket atau kuesioner merupakan teknik pengumpulan data yang dilakukan dengan cara memberi seperangkat pertanyaan atau pernyataan tertulis kepada responden untuk dijawab (Sugiyono, 2018). .Jenis yang digunakan dalam pengumpulan data penelitian ini adalah jenis angket tertutup, karena responden dalam hal ini siswa kelas VIII Palangka Raya Tahun ajaran 2018/2019 tinggal memilih dengan member jawaban $(\sqrt{ })$ pada jawaban yang telah disediakan dalam angket. Angket tertutup digunakan untuk mengungkap secara terperinci mengenai persepsi siswa terhadap layanan konseling dengan intensitas pemanfaatan layanan konseling individual di kelas VIII Palangka Raya. Langkah-langkah penyusunan angket (a) Merumuskan Tujuan

Sehubungan dengan masalah yang diteliti, maka angket ini bertujuan untuk mengumpulkan data tentang : (I) persepsi siswa terhadap bimbingan konseling ; (2) intensitas pemanfaatan layanan konseling individual. Dari variabelvariabel tersebut diatas dapat dirumuskan indikatorindikatornya, kemudian disusun item angket berdasarkan indikator tersebut. Menentukan skoring angket. Melakukan try out. Metode dokumentasi, Jadi dokumentasi adalah catatan-catatan tentang suatu peristiwa yang pernah terjadi, dimana catatan tersebut digunakan sebagai pertimbangan terhadap hal-hal yang akan datang, dalam penelitian ini dokumentasi digunakan untuk mengetahui keadaan siswa persepsi siswa terhadap layanan bimbingan konseling dan intemsitas pemanfaatan layanan konseling individual. Analisi data yang digunakan adalah teknik analisis statistik rumus "Product moment". Rumus statistik korelasi product moment adalah sebagai berikut:

$$
r_{x y}=\frac{N \Sigma x y_{-\left(\sum x\right)}\left(\sum y\right)}{\sqrt{\left(N \Sigma x^{2}-\left(\sum x\right)^{2}\left(N \Sigma y^{2}-(\Sigma y)^{2}\right)\right.}}
$$

Keterangan:

$r_{x y}=$ Koefisien korelasi antara jumlah skor item ganjil dengan jumlah skor genap

$\sum x^{2}=$ Jumlah kuadrat skor $\mathrm{X}$

$\sum y^{2}=$ Jumlah kuadrat skor $\mathrm{Y}$

$\mathrm{N} \quad=$ Jumlah sampel

Penguji Hipotesis

I. Ho atauhipotesa null diterimaapabila, nilai Z hitung $(\mathrm{Zh})$ adalah $1,96 \geq \mathrm{Z}(\mathrm{h}) \leq+1,96$ atau $r$ hitung $>r$ tabel.

2. Ha atau hipotesa alternative diterima apabila nilai $Z$ hitung $(Z(h))$ adalah $-I, 96 \leq Z(h) \geq+$ I,96 atau $r$ hitung $<r$ tabel.

\section{HASIL DAN PEMBAHASAN}

Dari hasil pengumpulan data tentang persepsi siswa terhadap layanan Bimbingan dan Konseling diperoleh nilai tertinggi 87 dan terendah 59 (lihat lampiran 13). Adapun dari analisis data diperoleh nilai mean $=77,25$ median $=$ 80,65 modus $=87,45$ dan standar deviasi $=7,395$ (lihat lampiran 14).Selanjutnya data tentang persepsi siswa terhadap layanan bimbingan konseling tersebut dapat digambarkan dalam tabel ftrekuensi sebagai berikut :

Tabel I. Distribusi Frekuensi Persebsi Siswa

Terhadap Layanan Bimbingan Konseling

\begin{tabular}{cccc}
\hline Nilai & $\mathbf{X}$ & $\mathbf{F}$ & $\mathbf{f X}$ \\
\hline $84-88$ & 86 & 10 & 860 \\
$79-83$ & 81 & 19 & 1377 \\
$74-78$ & 76 & 9 & 532 \\
$69-73$ & 71 & 8 & 355 \\
$64-68$ & 66 & 7 & 462 \\
$59-63$ & 61 & 19 & 122 \\
\hline Jumlah & & $\mathbf{N = 7 2}$ & $\mathbf{3 7 0 8}$ \\
\hline
\end{tabular}


M. Hariadi Akbar, Merson U. Sangalang \& Esty Pan Pangestie Jurnal Pandohop

Vol. I, No. I, Tahun 202I e-ISSN .xxxxxxxxx

Dari hasil pengumpulan data tentang intensitas pemanfaatan layanan konseling individual diperoleh nilai tertinggi 87 dan terendah 58 (lihat lampiran 15). Adapun dari analisis data diperoleh nilai mean $=73,94$ median $=78$ modus $=86,12$ dan standar deviasi $=8,98$

Selanjutnya data tentang intensitas pemanfaatan layanan konseling individual tersebut dapat digambarkan dalam tabel frekuensi sebagai berikut :

\section{Tabel 2. Tabel Distribusi Frekuensi Intensitas} Pemanfaatan Layanan Konseling Individual

\begin{tabular}{cccc}
\hline Nilai & $\mathbf{X}$ & $\mathbf{F}$ & $\mathbf{f X}$ \\
\hline $86-90$ & 88 & 9 & 264 \\
$81-85$ & 83 & 17 & 747 \\
$76-80$ & 78 & 8 & 1092 \\
$71-75$ & 73 & 6 & 511 \\
$66-70$ & 68 & 9 & 340 \\
$61-65$ & 63 & 14 & 189 \\
$56-60$ & 58 & 6 & 406 \\
\hline Jumlah & & $\mathbf{N}=\mathbf{7 2}$ & $\mathbf{3 5 4 9}$ \\
\hline
\end{tabular}

Dari hasil analisis data yaitu, antara persepsi siswa terhadap layanan konseling dengan Intensitas pemanfaatan layanan konseling individual dianalisis dengan statisticr produk moment diperoleh nilai rhitung yaitu sebesar $0,84 \mathrm{I}$. Selanjutnya nilai rhitung tersebut dikonsultasikan dengan rtabel produk moment dengan $\mathrm{N}=48$ dan taraf kebenaran I\% yaitu 0,368. Ternyata hasil analisis yaitu, 0,84I >0,368.

Dengan demikian hipotesis yang menyatakan bahwa "Ada hubungan antara persepsi siswa terhadap layanan konseling dan intensitas pemanfaatan layanan konseling individual di kelas VIII SMPN 9 Palangka Raya terbukti kebenarannya pada taraf signifikan I \%.

Dari pengujian hipotesis diatas ternyata hipotesis yang menyatakan bahwa "Ada Hubungan Antara Persepsi siswa terhadap layanan konseling dengan Intensitas pemanfaatan layanan konseling individual di kelas VIII SMPN 9 Palangka Raya Tahun Ajaran 2018/2019" diterima keberannya.

\section{KESIMPULAN}

Dari hasil analisis data yaitu antara persepsi siswa terhadap bimbingan konseling dengan intensitas pemanfaatan layanan konseling individual. Peneliti menyimpulkan ada hubungan antara persepsi siswa terhadap bimbingan konseling dengan intensitas pemanfaatan layanan konseling individual pada siswa kelas VIII SMPN 9 Palangka Raya Tahun Ajaran 2018/2019.

\section{REFERENSI}

Ardi, M. (20II). Hubungan Antara Persepsi Terhadap Organisasi Dengan Minat Berorganisasi Mahasiswa Fakultas Psikologi Uin Suska Riau. Universitas Islam Negeri Sultan Syarif Kasim Riau.

Pratama, R., Syahniar, S., \& Karneli, Y. (2016). Perilaku Agresif Siswa Dari Keluarga Broken Home. Konselor, 5(4).

Retnanto, A. (2015). Studi Korelasi Antara Bimbingan Pribadi Dengan Sikap Keberagamaan Siswa Smp Negeri I Kaliori-Rembang Tahun 2012. ELEMENTARY: Islamic Teacher Journal, 3(I).

Sugiyono. (2018). Metode Penelitian Kuantitatif,Kualitatif dan R\&D. In ke-26. 